\title{
Effect of Deformation on Precipitation and the Microstructure Evolution during Multistep Thermomechanical Processing of Al-Zn-Mg-Cu Alloy
}

\author{
Jinrong Zuo ${ }^{1,2, *(\mathbb{D}, \text {, Longgang Hou }}{ }^{3}$, Xuedao Shu ${ }^{1,2}{ }^{\mathbb{D}}$, Wenfei Peng ${ }^{1,2}$, Anmin Yin ${ }^{1,2}$ and \\ Jishan Zhang ${ }^{3}$ \\ 1 College of Mechanical Engineering and Mechanics, Ningbo University, Ningbo 315211, China; \\ shuxuedao@nbu.edu.cn (X.S.); pengwenfei@nbu.edu.cn (W.P.); yinanmin@nbu.edu.cn (A.Y.) \\ 2 Zhejiang Provincial Key Laboratory of Part Rolling Technology, Ningbo 315211, China \\ 3 State Key Laboratory for Advanced Metals and Materials, University of Science and Technology Beijing, \\ 30 Xueyuan Road, Haidian District, Beijing 100083, China; lghou@skl.ustb.edu.cn (L.H.); \\ zhangjs@skl.ustb.edu.cn (J.Z.) \\ * Correspondence: zuojinrong@nbu.edu.cn; Tel.: +86-0571-87600534
}

Received: 24 September 2020; Accepted: 21 October 2020; Published: 23 October 2020

\begin{abstract}
In order to obtain fine grained structure efficiently, a new multi-step rolling process (MSR: pre-deformation + intermediate annealing + hot deformation) was applied in $\mathrm{Al}-\mathrm{Zn}-\mathrm{Mg}$-Cu plates. Conventional hot rolling (CHR) was also carried out as a contrast experiment. The evolution of microstructures and improvement of mechanical properties were analyzed by optical microscope, scanning electron microscope, transmission electron microscope, $X$-ray diffractometer, and tensile tests. The results show that the MSR process can obtain finer longitudinal grain size and better mechanical properties than $\mathrm{CHR}$, which can be explained as follows: spheroidization of precipitates wrapped by high density dislocations could be promoted by increased pre-deformation; numerous ordered substructures were formed during short-period intermediate annealing at high temperature; in the subsequent hot rolling process, the retained spherical precipitates pinned dislocations and boundaries. With the increase of accumulated strain, low angle grain boundaries gradually transformed into high angle grain boundaries, leading to grain refinement. With the increased pre-deformation (MSR $120+60 \%, \mathrm{MSR}_{2} 40+40 \%, \mathrm{MSR}_{3} 60+20 \%$ ), the effect of grain refinement and plasticity improvement gradually weakened. The optimum thermomechanical process $\left(\mathrm{MSR}_{1}\right.$ solid solution + pre-deformation $\left(300^{\circ} \mathrm{C} / 20 \%\right)+$ intermediate annealing $\left(430^{\circ} \mathrm{C} / 5 \mathrm{~min}\right)+$ hot deformation $\left.\left(400{ }^{\circ} \mathrm{C} / 60 \%\right)\right)$ was obtained, which can increase elongation by $\sim 25 \%$ compared with the CHR process, while maintaining similar high strength for reduced longitudinal grain size.
\end{abstract}

Keywords: Al-Zn-Mg-Cu alloy; precipitates; hot rolling; microstructure; mechanical property

\section{Introduction}

Aluminum has been widely used in aerospace, construction, machinery manufacturing, chemical industry, electrical appliances, and other industries [1]. With the development of the industry, the requirements for strength, toughness, and light weight in aerospace are advancing to ever higher levels [2]. Therefore, Al-Zn-Mg-Cu alloys with excellent comprehensive properties, such as high strength-to-weight ratio, good toughness, and stress corrosion cracking resistance, has become one of the most important structural materials applied in aerospace, transportation, and other fields [3]. The main alloying elements of $7 x x x$ series high strength aluminum alloy are $\mathrm{Zn}, \mathrm{Mg}, \mathrm{Cu}, \mathrm{Zr}$, and impurity elements Fe and $\mathrm{Si}$ ( $\mathrm{Zn} \mathrm{7-12 \% ,} \mathrm{Mg} \mathrm{wt \%} \mathrm{2-3 \% ).} \mathrm{The} \mathrm{main} \mathrm{strengthening} \mathrm{phase} \mathrm{is} \mathrm{MgZn}_{2}$. Increasing the content of $\mathrm{Zn}$ and $\mathrm{Mg}$ can improve the strength, but decreases the toughness and SCC 
(stress corrosion resistance). 7xxx series aluminum alloy was developed on the basis of $\mathrm{Al}-\mathrm{Zn}-\mathrm{Mg}$ alloy. Due to serious stress corrosion, the Al-Zn-Mg alloy was limited in wide use until the addition of $\mathrm{Cu}$, Mn, and Cr. In the 1990s, the Alcoa company further increased Zn content on the basis of 7150 alloy composition, to develop the 7055 aluminum alloy under the requirements of maintaining durability and damage tolerance, while improving the strength. Precipitation strengthening is the most effective method for $\mathrm{Al}-\mathrm{Zn}-\mathrm{Mg}-\mathrm{Cu}$ alloy. It refers to the strengthening effect caused by the precipitation of the second phase particles, also known as age strengthening. Its physical essence can be explained by the interaction theory between dislocations and second phase particles (the second phase particles and their stress field interact with dislocations and hinder the movement of dislocations). However, the existing $\mathrm{Al}-\mathrm{Zn}-\mathrm{Mg}-\mathrm{Cu}$ alloys still have some shortcomings, such as coarse grains, uneven microstructures, and poor plasticity [2], which may limit their wide application and development.

Strength is one of the most important basic mechanical properties of alloys, and can be significantly improved by adding elements to obtain more strengthening phases [4]. However, plasticity and hot workability of the alloy will be greatly deteriorated [5-7]. Fortunately, the decrease of plasticity can be compensated by grain refinement [8,9]. Grains can be micronized or even nano-sized by ECAP (equal channel angular pressing) [10], MDF (multi-directional forging), [11] and CR (cryogenic rolling) [12], but these methods are hard to apply in mass production of large-scale plates, due to the complex process (severe plastic deformation of ECAP or MDF), and high environmental requirements (ultra-low deformation temperature of CR). Thermomechanical processing (TMP) is a strengthening and toughening method, combining deformation and phase transformation to improve the comprehensive properties of aluminum alloy [13]. TMP can increase defect density and modify their arrangement, which affects the nucleation kinetics and distribution of precipitates. Meanwhile, these newly formed precipitates pin and retard the movement of dislocations, stabilize these defects, and refine microstructures, thus improving strength and toughness of the alloy [14]. Yan et al. [15] investigated the effect of deformation temperature on the microstructure and mechanical properties of 7055 aluminum alloy under total strain of 1.6, and found that the sample exhibited a highest ultimate tensile strength of $608 \mathrm{MPa}$ and elongation of $12.5 \%$, with $45 \%$ recrystallization grains at the deformation temperature of $400{ }^{\circ} \mathrm{C}$.

Russo et al. [16] had developed a new TMP for $7075 \mathrm{Al}$ alloy (homogenized + deformed at $330{ }^{\circ} \mathrm{C}$ and quenched rapidly + recrystallization) to eliminate casting defects and obtain fine grains. The related mechanism was that part of the second phase (chromium rich particles) was dissolved into the matrix during homogenization treatment, and the residue coarse pinned dislocations, to form dislocation stacking during deformation. Therefore, deformation around the coarse second phase particles was more severe, and recrystallization was easier around these coarse second phase particles during subsequent recrystallization treatment. In addition, some stable fine particles were retained after homogenization and distributed at dislocation, sub-grain boundaries and recrystallization grain boundaries, which hindered the boundaries migration. Finally, grains were refined [16]. During TMPs, strain and precipitation, and their interaction, play very important roles. However, these precipitates are not directly involved in the final age strengthening, for all experimental and control samples undergo solutionizing and aging heat treatment after the rolling procedures, destroying any potential differences in strengthening precipitate distribution. The precipitates only play an auxiliary role in grain refinement. Such a process is also called intermediate thermomechanical treatment (ITMP). Waldman et al. [17], improved the process of Russo, E.D. After homogenization, the ingot was furnace cooled, hot rolled, and recrystallized, a similar fine recrystallization structure could be obtained. Wert et al. [18], developed another ITMP process on the basis of the former two. After solution treatment and water quenching, plates were aged for a long time at high temperature. When the size of precipitates reached $0.75-1 \mu \mathrm{m}$, water cooling was carried out. Plates were then warm rolled with $90 \%$ height reduction, and finally the deformed plates were rapidly heated to the solution temperature. Static recrystallization occurred, and grains were refined. Superplastic plate was successfully manufactured in this way. Esmaeili et al. [19] refined grains of 6xxx series Al alloy by solution natural aging, cold 
rolling ( $80 \%$ deformation), and non-isothermal recrystallization annealing (heat rate $0.4{ }^{\circ} \mathrm{C} / \mathrm{min}$, starting temperature $50{ }^{\circ} \mathrm{C}$, and ending temperature $380^{\circ} \mathrm{C}$ ). Grain size of the final plate was about $11 \mu \mathrm{m}$ on the rolling surface, and $8 \mu \mathrm{m}$ in the cross section. with uniform distribution. Grain refinement can be achieved by the above-mentioned ITMPs, and the anisotropy can be reduced while maintaining high strength.

However, some shortcomings still exist in existing ITMPs: It takes a long time overaging at high temperature to obtain enough large particles, which is time and energy consuming; It is difficult to deform more than $80 \%$ at low temperature $\left(220-300{ }^{\circ} \mathrm{C}\right)$, especially in the center of ultra-high strength $\mathrm{Al}-\mathrm{Zn}-\mathrm{Mg}-\mathrm{Cu}$ alloys; The coarse particles obtained by overaging are difficult to re-dissolve completely in a short time during the later solid solution. Additionally, the existing ITMPs are still complex and difficult to apply to large-scale production, so it is necessary to optimize the ITMPs. Therefore, this paper studied the interaction between deformation and precipitation, and developed a new ITMP (MSR: Pre-deformation + SIA (short period intermediate annealing) + final hot rolling) to obtain grain refinement. The MSR process, pre-deformation, intermediate annealing, and final hot deformation are combined to realize the coordinated control of grain refinement and precipitation behavior, and finally achieve good strength and plasticity. Pre-deformation was used to replace the long-term high-temperature overaging of traditional ITMPs, which is time and energy saving. The main deformation stage was set at a high temperature $\left(400^{\circ} \mathrm{C}\right)$ instead of the low-temperature deformation $\left(220-300{ }^{\circ} \mathrm{C}\right)$ of traditional TMPs, leading to small deformation resistance and good formability. The size of the deformation induced precipitates was less than $200 \mathrm{~nm}$, which were be easier to re-dissolve in the final short-term solution, leading to better mechanical properties. Plasticity of the plate was significantly improved, without sacrificing strength. The effect of pre-deformation (MSR $1: 20 \%, \mathrm{MSR}_{2}: 40 \%, \mathrm{MSR}_{3}: 60 \%$ ) on the morphology, area fraction of precipitates, the evolution of microstructure, and the properties of the whole process were studied. A grain refinement model of MSR was built as well.

\section{Materials and Methods}

Hot rolled commercial $7055 \mathrm{Al}$ alloy plates (Length $75 \mathrm{~mm}$, width $30 \mathrm{~mm}$, thickness $15 \mathrm{~mm}$ cut in the middle of $80 \mathrm{~mm}$ thick plate, and keeping the rolling direction consistent) with the chemical composition given in Table 1 ( $\mathrm{Zn}, \mathrm{Mg}, \mathrm{Cu}, \mathrm{Fe}, \mathrm{Zr}$, Ti by IC-AES (electron-coupled plasma atomic emission spectrum), Si by spectrophotometry) were used in this experiment.

Table 1. Chemical composition of AA 7055 alloy ( $w t \%)$.

\begin{tabular}{ccccccccc}
\hline Element & $\mathbf{Z n}$ & $\mathbf{M g}$ & $\mathbf{C u}$ & $\mathbf{Z r}$ & $\mathbf{T i}$ & $\mathbf{F e}$ & $\mathbf{S i}$ & $\mathbf{A l}$ \\
\hline$w t \%$ & 8.38 & 2.07 & 2.31 & 0.13 & 0.16 & 0.092 & 0.056 & $\mathrm{Bal}$ \\
\hline
\end{tabular}

According to the temperature-precipitates diagram of $\mathrm{Al}-\mathrm{Zn}-\mathrm{Mg}-\mathrm{Cu}$ alloy [19], and the correlation constants of the main precipitates [20,21], it can be seen that the volume fraction of $\mathrm{M}$ phase (i.e., $\mathrm{MgZn}_{2}$ ) gradually decreases, while that of $\mathrm{S}-\mathrm{Al}_{2} \mathrm{CuMg}$ phase increases gradually in the range of $210-435^{\circ} \mathrm{C}$; the volume fraction of $\mathrm{S}$ phase decreases gradually in the range of $435-470{ }^{\circ} \mathrm{C}$. That means $\mathrm{Al}-\mathrm{Zn}-\mathrm{Mg}-\mathrm{Cu}$ alloy can be regarded as a single-phase solid solution in the temperature range of $470-490^{\circ} \mathrm{C}$; however, when temperature is higher than $490^{\circ} \mathrm{C}$, liquid phase appears, i.e., overburning occurs. Therefore, the optimal solution temperature should be between $470{ }^{\circ} \mathrm{C}$ and $490^{\circ} \mathrm{C}$ (the interval of single-phase solid solution). The optimum double step $\left(470{ }^{\circ} \mathrm{C} / 16 \mathrm{~h}+475^{\circ} \mathrm{C} / 8 \mathrm{~h}\right)$ initialized solution treatment was adopted. After long-term solution treatment, plates were water quenched at room temperature (quenching transfer time less than $10 \mathrm{~s}$ ). Then, the plates were processed by two routes, shown in Figure 1, with the specific process parameters in Table 2. Route A MSR (Figure 1a): After $20 \rightarrow 60 \%$ $\left(15 \rightarrow 12-6 \mathrm{~mm}\right.$ ) rolling pre-deformation at $300{ }^{\circ} \mathrm{C}$ (according to the $\mathrm{Al}-\mathrm{MgZn}_{2}$ pseudo-binary system in our former work [22], the optimum pre-deformation temperature could be set at $300{ }^{\circ} \mathrm{C}$, at which 
there was, not only rapid precipitation rate and small deformation resistance, but also a good pinning effect could be obtained), plates were heated to $430{ }^{\circ} \mathrm{C}$ (It has been proved that $430{ }^{\circ} \mathrm{C}$ cis the optimum temperature for dislocation migration and dislocations rearrangement in our former work $[23,24])$ for $5 \mathrm{~min}$ annealing, and then rolled at $400{ }^{\circ} \mathrm{C}$ (consistent with that of the CHR process for comparison) for $60 \rightarrow 20 \%(12 \sim 6 \rightarrow 3 \mathrm{~mm})$ final deformation. After 7 passes, the total deformation was $80 \%$, with the final plate thickness about $3 \mathrm{~mm}(15 \rightarrow 3 \mathrm{~mm})$. Route B CHR (Figure 1b): SQ-7055 Al plates were rolled for 7 passes at $400{ }^{\circ} \mathrm{C}$ for $80 \%$ rolling deformation $(15 \rightarrow 3 \mathrm{~mm})$, and were reheated for 10 min every two passes to retain hot rolling temperature. The hot deformation temperature of route A CHR was set at $400{ }^{\circ} \mathrm{C}$ to obtain good microstructure and mechanical properties, according to Yan et al. [15]. All rolled plates (both CHR and MSR) were solution treated at $475{ }^{\circ} \mathrm{C}$ for $0.5 \mathrm{~h}$ (water quenched at room temperature) and aged at $120^{\circ} \mathrm{C}$ for $24 \mathrm{~h}$ (T6). The microstructures of samples (e.g., (sub) grain, orientation, second phase, dislocations) were observed by optical microscopy (OM, Zeiss mc80dx, Carl Zeiss AG, Jena, Germany), transmission electron microscopy (TEM, Hitachi H800 and tecnaig2 F30, Hitachi, Tokyo, Japan), scanning electron microscopy (SEM, Zeiss ultra 55, Carl Zeiss AG, Jena, Germany), and X-ray diffraction (XRD, Philips apd210, Philips, Amsterdam, The Netherlands). Size and area fraction of precipitates were counted by the software "Image J". SEM only measures the micron-scale particles. Therefore, the statistics of precipitates were obtained by several TEM images. When the size of precipitates grew to micron-scale, they could be identified by SEM. the changing trends were also verified by SEM images. In order to reduce the effect of error, 3 random TEM images were taken as the average value. Tensile testing was carried out by mechanical testing and simulation (MTS-810, MTS Systems Corporation, Eden Prairie, MN, USA) was used to test mechanical properties at room temperature. The metallographic samples were etched with Keller's reagent $\left(2.5 \% \mathrm{HNO}_{3}+\right.$ $1.5 \% \mathrm{HCl}+1 \% \mathrm{HF}+95 \% \mathrm{H}_{2} \mathrm{O}$, vol\%) (Adamas, Shanghai, China). EBSD samples were mechanically and electropolished. The electrolyte was a mixture of $5 \% \mathrm{HClO}_{4}$ (Adamas, Shanghai, China) and $95 \%$ $\mathrm{C}_{2} \mathrm{H}_{5} \mathrm{OH}$ (Adamas, Shanghai, China), the voltage was $30 \mathrm{~V}$, and temperature was from -20 to $-30^{\circ} \mathrm{C}$. The Software "Channel 5" (1st, Oxford Instruments, Oxford, U.K.) was used to analyze the EBSD results. Grain boundaries with misorientation $<2^{\circ}$ could be ignored, with orientations of $2^{\circ}<\theta<15^{\circ}$ defined as LAGBs (LAGBs: Low angle grain boundaries, represented by gray lines), with orientations of $\theta>15^{\circ}$ as HAGBs (HAGBs: high angle grain boundaries, represented by black lines). TEM samples were prepared by mechanical grinding the $3 \mathrm{~mm}$ diameter sheet to $100 \mu \mathrm{m}$, and then thinning by twin-jet electropolishing. The electrolyte was $20 \% \mathrm{HNO}_{3}$ and $80 \% \mathrm{CH}_{3} \mathrm{OH}$ (vol \%) (Adamas, Shanghai, China), current was 80-100 mA, and temperature was from -20 to $-30{ }^{\circ} \mathrm{C}$. All OM, SEM, EBSD, and TEM were sampled from RD-ND (rolling direction was the normal direction of the cross section) at the mid-thickness layer of the plates.

(a)

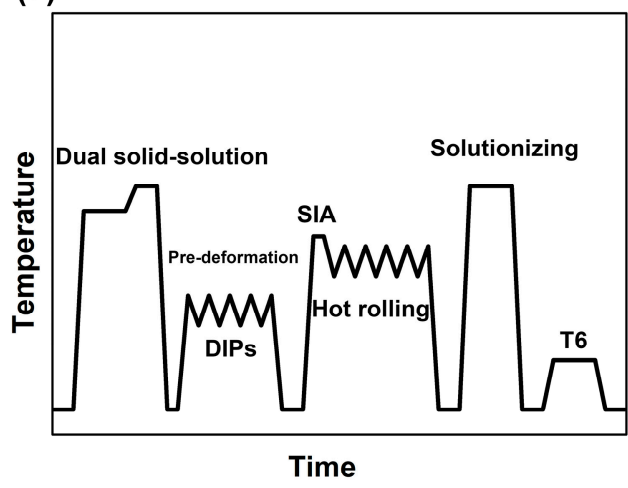

(b)

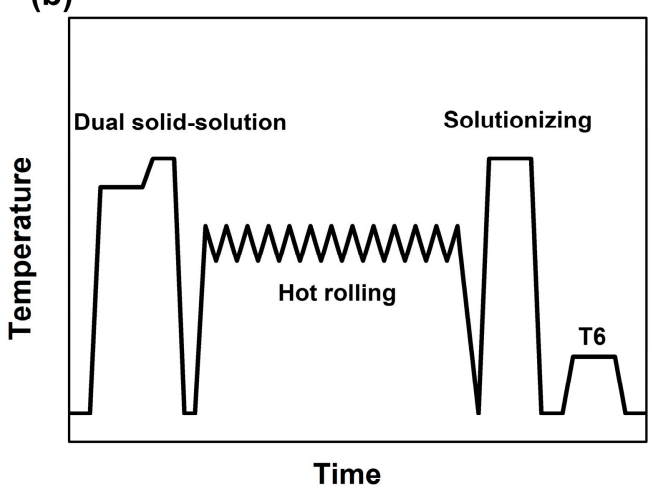

Figure 1. Schematic presentation of thermomechanical processings (TMPs): (a) MSR; (b) CHR. 
Table 2. Specific process parameters.

\begin{tabular}{cccc}
\hline Process & Pre-Deformation & SIA & Final Hot Rolling \\
\hline $\mathrm{CHR}$ & - & - & $400{ }^{\circ} \mathrm{C} / 80 \%$ \\
$\mathrm{MSR}_{1} 20+60 \%$ & $300^{\circ} \mathrm{C} / 20 \%$ & & $400{ }^{\circ} \mathrm{C} / 60 \%$ \\
& $15 \rightarrow 12 \mathrm{~mm}$ & $42 \rightarrow 3 \mathrm{~mm}$ \\
$\mathrm{MSR}_{2} 40+40 \%$ & $300^{\circ} \mathrm{C} / 40 \%$ & $430{ }^{\circ} \mathrm{C} / 5 \mathrm{~min}$ & $400{ }^{\circ} \mathrm{C} / 40 \%$ \\
& $15 \rightarrow 9 \mathrm{~mm}$ & & $9 \rightarrow 3 \mathrm{~mm}$ \\
$\mathrm{MSR}_{3} 60+20 \%$ & $300^{\circ} \mathrm{C} / 60 \%$ & $400{ }^{\circ} \mathrm{C} / 20 \%$ \\
& $15 \rightarrow 6 \mathrm{~mm}$ & $6 \rightarrow 3 \mathrm{~mm}$ \\
\hline
\end{tabular}

Note: Pre-deformation—1st step warm rolling, SIA—short time intermediate annealing, final hot rolling—2nd step hot rolling, CHR—conventional hot rolling, MSR—-multistep step hot rolling.

\section{Results and Discussion}

\subsection{Microstructure of the Initial Solutionized 7055 Al Alloy}

In order to make research meaningful, the initial alloy should return to the homogenization state before hot deformation, that is, the solid solution alloy with uniform microstructure and no segregation. Simultaneously, it is also necessary to ensure that the alloy does not overburn.

The microstructure of the alloy, after initial solution treatment, is shown in Figure 2. It is obvious that static recrystallization occurred during solution treatment. Therefore, some equiaxed grains appeared (Figure 2). However, because of the lack of driving force, the recrystallization was incomplete, so strip-shaped grains were still dominant, with longitudinal $\geq 600 \mu \mathrm{m}$, and transverse $\geq 200 \mu \mathrm{m}$. There was no obvious overburning in the alloy [25], precipitates were dissolved back with more clear grains, shown in Figure 2a. Still some insoluble coarse second phase particles remained at the grain boundaries.
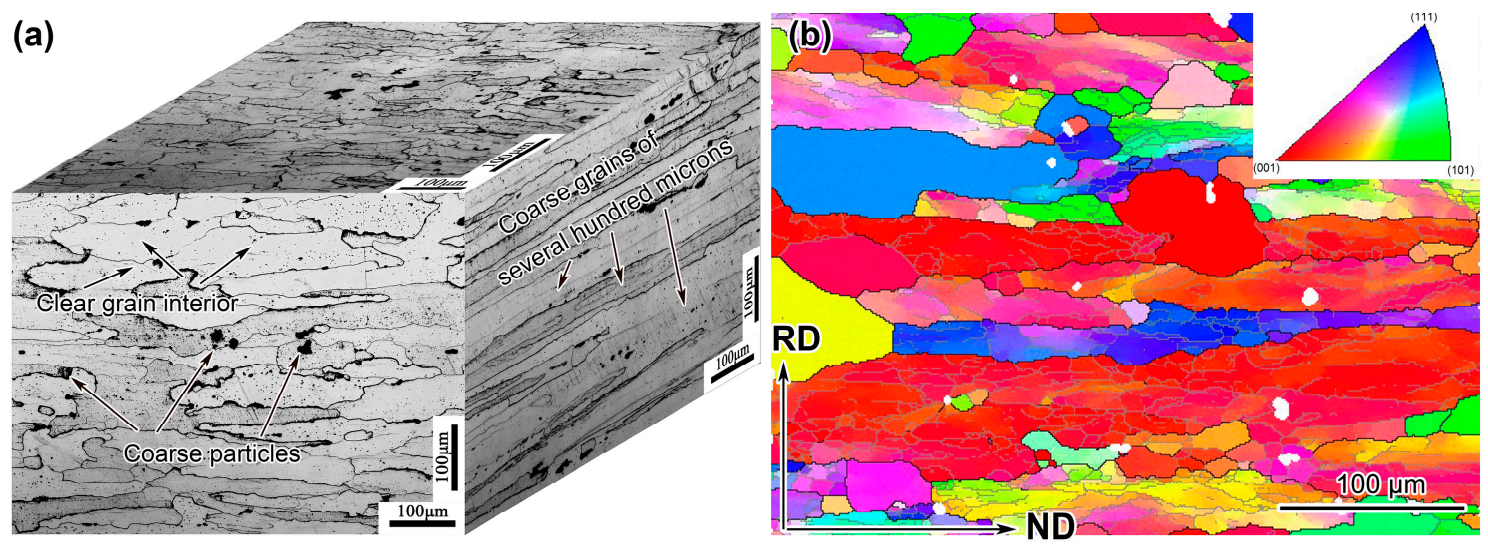

Figure 2. 3D-OM (a) and EBSD (b) of SQ-7055.

The distribution of high angle grain boundaries (HAGBs) and low angle grain boundaries (LAGBs) of SQ-7055 is shown in Figure 2b. Obvious recrystallization occurred in the alloy, no LAGBs with gray thin lines appeared in the recrystallized grains interior. Grain orientation was still dominated by $\{001\}$, and the recrystallization volume fraction was $28.6 \%$. High-density LAGBs appear inside the elongated grains.

\subsection{Evolution of Microstructures during TMPS}

The purpose of $20 \rightarrow 60 \%$ pre-deformation of MSR at $300^{\circ} \mathrm{C}$ is to obtain sufficient DIPs (Deformation Induced Precipitates) and dislocation accumulation required by the subsequent TMPs. The solid solution state of supersaturated aluminum alloys (such as $7055 \mathrm{Al}$ alloy) is unstable. The decomposition of supersaturated solid solution, and desolvation of solute atoms, can be caused by aging treatment or 
deformation under solution temperature, thus affecting the morphology, distribution, and density of precipitates [26].

Figure 3 is SEM images of $7055 \mathrm{Al}$ alloy during TMPs (with embedded TEM images, the white spots in TEM are the precipitates corroded by twin-jet electropolishing). It can be seen from Figure 3(a1) that rod/spherical precipitates along a certain direction were formed after $300{ }^{\circ} \mathrm{C} / 20 \%$ warm rolling (pre-deformation) of SQ-7055 Al alloy. With the increased pre-deformation, the size of precipitates increased, while their density decreased (Figure 3(a1-a3)). Spherical precipitates increased while the rod-shaped decreased, as shown in Figure 3(a2,a3). In precipitation strengthening $\mathrm{Al}$ alloy, the precipitation and growth of particles is a composite process of thermodynamics and kinetics. With the increased deformation, more defects (such as vacancies, dislocations, deformation bands, etc.) were introduced. These defects, with large structural fluctuation, would become the rapid diffusion channels of solute atoms, which accelerated the atomic diffusion and promoted the growth of precipitates. Therefore, the size of precipitates increased with deformation. The size and area fraction of precipitates, obtained after different pre-deformations, were statistically analyzed. It was found that with increased pre-deformation from $20 \%$ to $40 \%$, and $60 \%$, size of precipitates increased from $33 \mathrm{~nm}$ to $46 \mathrm{~nm}$, and $58 \mathrm{~nm}$, while their density decreased, but the area fraction maintained similar $(5.8 \%, 5.6 \%$, and $5.9 \%$, respectively, with pre-deformation). As mentioned above, the fast diffusion channels of solute atoms can be formed through numerous defects introduced by strain, which affects the precipitation and re-desolution rate of the second phase particles. However, from the thermodynamic point of view, the solubility of solid solution is affected by temperature. Therefore, the total amount of precipitates (i.e., the area fraction), should also be determined by temperature under the condition of equilibrium state [27]. Strain can only affect the morphology and size of precipitates.

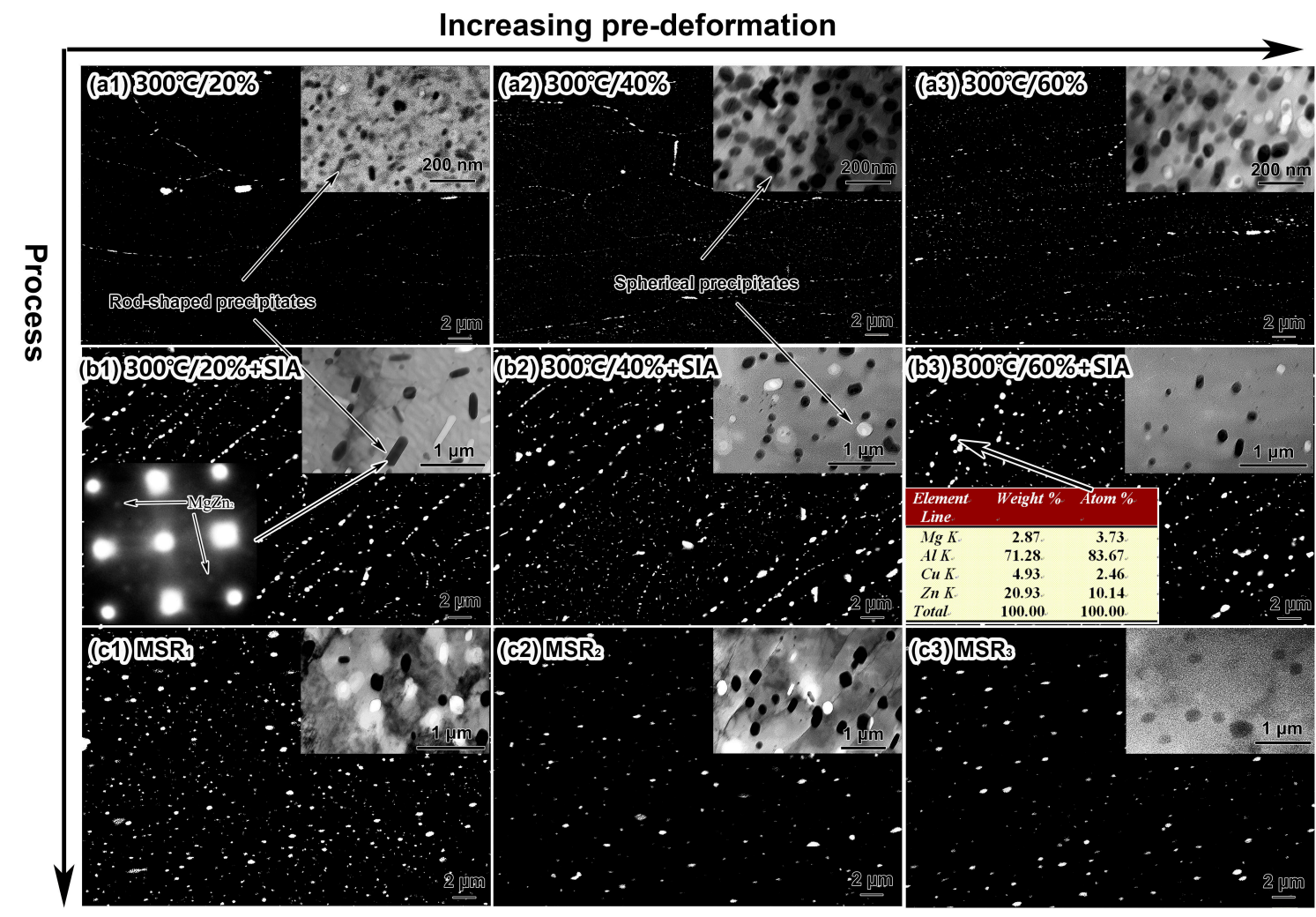

Figure 3. SEM images (by backscattered electron) with embedded TEM images of precipitates: (a1) $300{ }^{\circ} \mathrm{C} / 20 \%$; (a2) $300{ }^{\circ} \mathrm{C} / 40 \%$; (a3) $300{ }^{\circ} \mathrm{C} / 60 \%$; (b1) $300{ }^{\circ} \mathrm{C} / 20 \%$ + SIA (with embedded SAED (selected area electron diffraction) patterns); (b2) $300{ }^{\circ} \mathrm{C} / 40 \%+\mathrm{SIA} ;$ (b3) $300{ }^{\circ} \mathrm{C} / 60 \%+$ SIA (with embedded EDS results); (c1) $\mathrm{MSR}_{1} ;$ (c2) $\mathrm{MSR}_{2} ;$ (c3) $\mathrm{MSR}_{3}$. 
In our previous work, it was proved that the second phase particles play a very important role [24,28,29] during TMPs. In this paper, the DIPs (deformation induced precipitates) obtained by pre-deformation also affected microstructure of the subsequent intermediate annealing. The pre-deformed samples then annealed at $430{ }^{\circ} \mathrm{C}$ for $5 \mathrm{~min}$, morphology of precipitates changed as shown in Figure 3(b1-b3). Precipitates in $\left(300{ }^{\circ} \mathrm{C} / 20 \%+\right.$ SIA) samples were rod-shaped or spherical, with the rod length of 200-500 nm, and a width of 50-150 nm (Figure 3(b1)). With increased pre-deformation, precipitates were gradually refined and spheroidized (Figure 3(b2,b3)). According to the embedded DIPs SAED, in Figure 3(b1), and EDS results, in Figure 3(b3), DIPs were proved to be $\mathrm{MgZn} 2$ phase.

When new phases are precipitated from a parent phase, the change of Gibbs free energy during the whole process can be expressed as follows [30,31]:

$$
\Delta G=V \Delta G_{\mathrm{V}}+V \Delta G_{\varepsilon}+A \gamma
$$

where $V$ is the volume of new phase, $\Delta G_{\mathrm{V}}$ is the free energy difference between new phase and parent phase per unit volume, $\Delta G_{\varepsilon}$ is the strain energy of new phase per unit volume, $\mathrm{A}$ is the total interfacial area of new phase, and $\gamma$ is the interfacial energy between new phase and parent phase.

The area fraction of $\mathrm{MgZn}_{2}$ phase in $7055 \mathrm{Al}$ alloy remains unchanged under different deformations. Therefore, $V, \Delta G_{\mathrm{V}}$, and $A$ are constant under different TMPs. The value of $\Delta G$ is determined by the relationship between $\gamma$ and $\Delta G_{\varepsilon}$. As shown in Figure 3(a1,b1), strain energy $\left(\Delta G_{\varepsilon}\right)$ is the main factor during deformation at $300{ }^{\circ} \mathrm{C}$ for $20 \%$, so precipitates are rod-shaped. Defects induced by deformation also increase with deformation. When new phase particles precipitated at these defects, the defects were destroyed or disappeared, thus reducing the Gibbs free energy of the system [32].

When large deformation is introduced, the change of Gibbs free energy of the whole system can be expressed as [31,32]:

$$
\Delta G^{\prime}=V \Delta G_{\mathrm{V}}+V \Delta G_{\varepsilon}+A \gamma+V \Delta G_{\mathrm{B}}
$$

where $\Delta G_{\mathrm{B}}$ is the decrease of Gibbs free energy per unit volume (due to the introduction of abundant defects, the free energy will be reduced due to the precipitation at these defects).

The critical nucleation radius $r^{*}$ of precipitates can be expressed as [32,33]:

$$
r *=2 \gamma /\left(\Delta G_{\mathrm{V}}+\Delta G_{\varepsilon}+\Delta G_{\mathrm{B}}\right)
$$

with the increased $\Delta G_{\mathrm{B}},\left(\Delta G_{\mathrm{V}}+\Delta G_{\varepsilon}+\Delta G_{\mathrm{B}}\right)$ increases and $r^{*}$ decreases, which leads to the increase of driving force $\Delta G^{\prime}$ and the quantity of nucleation. Therefore, the surface energy (interfacial energy) plays a more important role than the strain energy. Moreover, the surface energy of spherical particles is the lowest, so the spheroidization of precipitates will be promoted after large deformation (Figure 3(a2,a3,b2,b3)).

Figure 3(c1-c3) shows SEM (TEM) images of the final-rolled $7055 \mathrm{Al}$ alloy by different TMPs. With decreased deformation in the final hot rolling stage $\left(\mathrm{MSR}_{1} \rightarrow \mathrm{MSR}_{3}\right)$, the size of precipitates almost remains unchanged, but their density decreases. After statistics, it was found that the size of precipitates by different TMPs was similar $\left(\mathrm{MSR}_{1}: 110 \mathrm{~nm} ; \mathrm{MSR}_{2}: 140 \mathrm{~nm} ; \mathrm{MSR}_{3}: 150 \mathrm{~nm}\right)$ while their area fraction decreased from $\mathrm{MSR}_{1}$ to $\mathrm{MSR}_{3}\left(\mathrm{MSR}_{1}: 6.2 \% ; \mathrm{MSR}_{2}: 5.1 \% ; \mathrm{MSR}_{3}: 4.4 \%\right)$. Compared with the final hot rolling temperature, pre-deformation temperature was relatively lower $\left(300<400{ }^{\circ} \mathrm{C}\right)$, the atom movement was slow, and dislocation was inactive. Therefore, under the same deformation, the accumulated defects are more than those in the final hot rolling. These defects form fast diffusion channels, and accelerate the dissolution of precipitates during hot rolling. Thus, the larger the pre-deformation, the more defects can be accumulated, which leads to a faster re-dissolution rate of DIPs in the high temperature hot rolling stage.

The pinning force of precipitates on boundaries can be expressed as [34]:

$$
P_{\mathrm{Z}}=3 F_{\mathrm{V}} \gamma_{\mathrm{b}} / d
$$


$P_{\mathrm{Z}}$ : Zener drag force, $F_{\mathrm{V}}$ : Volume fraction of precipitates, $\gamma_{\mathrm{b}}$ : Constant, $d$ : Average diameter of precipitates.

The area fraction of precipitates decreases gradually from $\mathrm{MSR}_{1}$ to $\mathrm{MSR}_{3}$ (Figure 3(c1-c3)), but their sizes are similar, i.e., $\gamma_{\mathrm{b}}$ and $d$ remain unchanged while $F_{\mathrm{V}}$ decreases. Therefore, during the hot rolling process, the pinning force of precipitates on boundaries gradually weakens.

Figure 4 shows the EBSD with embedded TEM images of (sub) grain structures. After deformation at $300{ }^{\circ} \mathrm{C}$ for $20 \%$, dislocations were pinned by precipitates (Figure 4(a1), insert map). When deformation increased to $40 \%$, more defects (such as dislocations) were introduced, dynamic recovery occurred, and dislocation cells were formed (Figure 4(a2)). With continued increasing of the deformation to $60 \%$, dislocation cells grew up, but their boundaries were still pinned by precipitates, hard to form clear-cut subgrains (Figure 4(a3)). During the SIA process, the redissolution of precipitates, and recovery also affect substructures. The growth of precipitates follows the Ostwald ripening principle (smaller particles dissolve while larger grow up [35]). The remaining fine precipitates (incompletely dissolved) will continue to pin boundaries, while the fully dissolved or coarsened precipitates will lose their pinning effect. The (sub)grain boundaries and dislocations, without pinning hindrance become active, resulting in static recovery. Figure 4(b1-b3) embedded images show TEM images of substructure morphology of different samples after SIA treatment. At $300{ }^{\circ} \mathrm{C} / 20 \%+\mathrm{SIA}$, samples underwent static recovery and dislocation rearrangement to form an ordered dislocation array. Banded structures (composed of dislocation array) were formed along the direction at about $45^{\circ}$ to grain boundaries (Figure 4(b1)). With the increase of deformation, these banded structures gradually become equiaxed, and subgrains with clear boundaries were formed when deformation reached $60 \%$ (Figure $4(\mathrm{~b} 2)$ ).

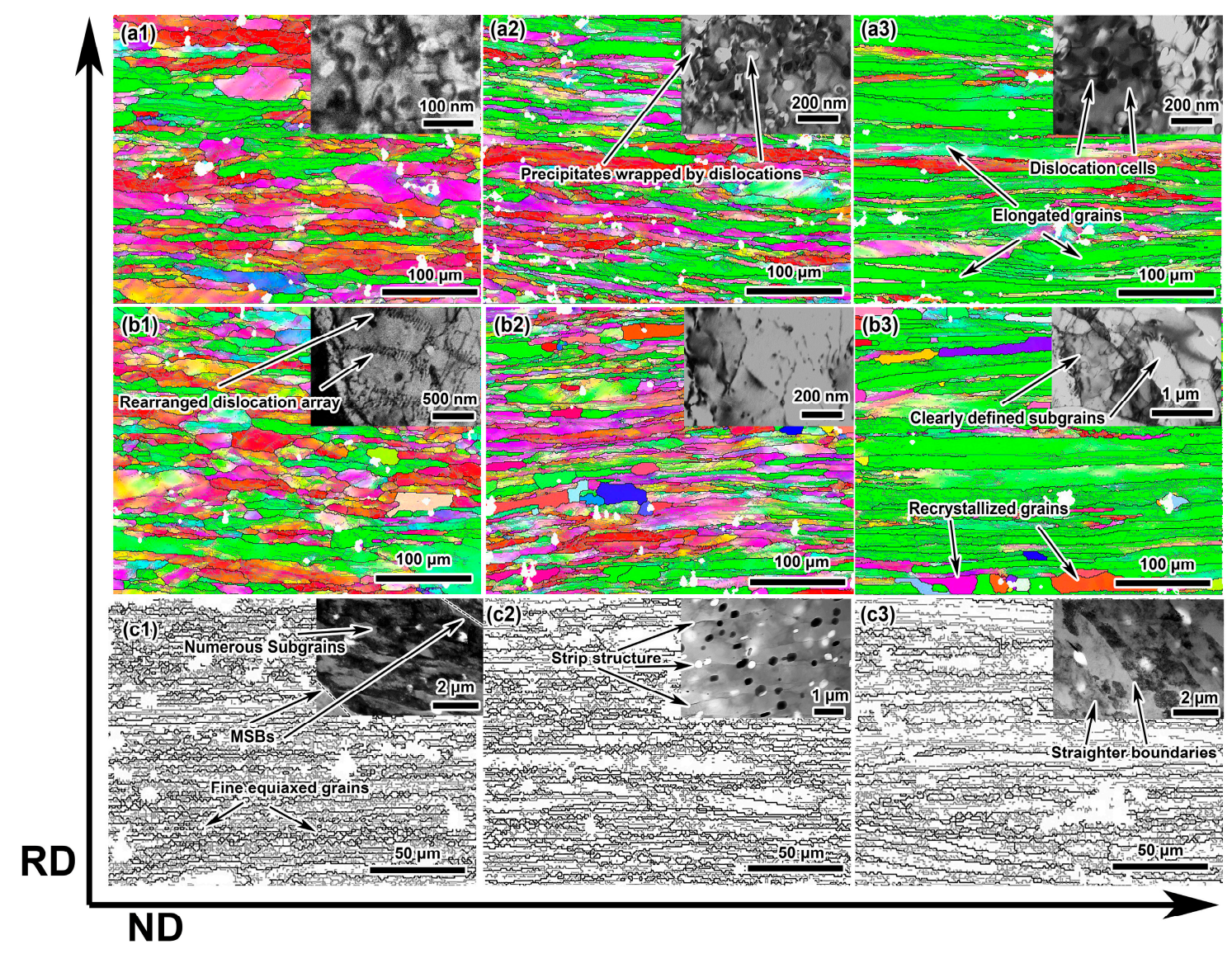

Figure 4. EBSD with embedded TEM images of (sub) grain structure: (a1) $300{ }^{\circ} \mathrm{C} / 20 \%$; (a2) $300{ }^{\circ} \mathrm{C} / 40 \%$; (a3) $300{ }^{\circ} \mathrm{C} / 60 \%$; (b1) $300{ }^{\circ} \mathrm{C} / 20 \%+\mathrm{SIA}$; (b2) $300{ }^{\circ} \mathrm{C} / 40 \%+\mathrm{SIA}$; (b3) $300{ }^{\circ} \mathrm{C} / 60 \%+\mathrm{SIA}$; (c1) $\mathrm{MSR}_{1}$; (c2) $\mathrm{MSR}_{2} ;(\mathrm{c} 3) \mathrm{MSR}_{3}$. 
SIA (annealing at $430^{\circ} \mathrm{C}$ ) can be considered as a high temperature recovery treatment (temperature $>0.6 \mathrm{~T}_{\mathrm{m}}, \mathrm{T}_{\mathrm{m}}$ : melting point of $7055 \mathrm{Al}$ alloy, under which edge dislocations can obtain enough energy to climb), which can lead to the following results: Irregular dislocations were rearranged to form dislocation walls, for the reduction of elastic distortion energy (Figure 4(b1)); Partial dislocation walls (along the direction perpendicular to the slip plane, and with a certain orientation difference) were polygonal, and formed subgrains (Figure 4(b2,b3)). In the recovery stage, the driving force of polygonization came from the decrease of deformation storage energy, so the polygonal degree increases with deformation, and subgrains with clear boundaries were formed finally [32]. After SIA, fine precipitates (retained due to Ostwald role) could still pin boundaries, and a large quantity of sub-structures formed by static recovery at this stage, which underwent certain transformations in the final hot rolling, resulting in grain refinement (Figure 4(c1-c3)). Figure 4(c1) shows that in addition to forming a large quantity of subgrains, micro shear bands (MSBs) were observed after $\mathrm{MSR}_{1}$ treatment, which are composed of a number of regularly arranged fine subgrains. According to Hurley P.J. [36] MSBs are transformed from deformation bands. MSBs can increase the fraction of LAGBs, refine subgrains, and become the preferred nucleation sites in the subsequent recrystallization treatment [36,37]. With decreased high-temperature deformation, clear banded structures were obtained by $\mathrm{MSR}_{2}(40+40 \%)$, and precipitates were distributed along boundaries of the strip structure (Figure 4(c2)). When the high-temperature deformation reduced to $20 \%\left(\mathrm{MSR}_{3} 60+20 \%\right)$, the banded structures were more obvious, and boundaries were straighter due to severe recovery (the reduction of pinning force) (Figure 4(c3)).

After pre-deformation, grains of all alloys were elongated (Figure 4(a1-a3)). A few equiaxed grains remained near the elongated grain boundaries. With the increased pre-deformation $(20 \rightarrow 60 \%)$, dynamic recovery was more serious, grain boundaries became straighter, grain widths became narrower, and the orientation was gradually closer to $\{101\}$.

After short-time high-temperature intermediate annealing at $430^{\circ} \mathrm{C}$, obvious static recovery (the appearance of subgrains and increase of grain width) and static recrystallization (the formation of fine equiaxed grains) occurred (Figure 4(b1-b3)). Compared with SQ-7055, grain size was refined. However, due to lack of deformation storage energy, the complete recrystallization cannot take place, so strip-shaped grains were still dominant. With increased pre-deformation, dynamic recovery was more serious, with wider grain size.

After the final hot rolling $\left(400^{\circ} \mathrm{C}\right)$, obvious fibrous deformed ribbons were obtained. Fine equiaxed grains appeared near the original grain boundaries (Figure $4(\mathrm{c} 1-\mathrm{c} 3)$. The reason is that numerous substructures generated by SIA changed under the subsequent hot rolling (high temperature $400{ }^{\circ} \mathrm{C}$ and accumulated large deformation 80\%). Activity of boundaries increased, and the LAGBs (subgrains) gradually stabilized and transformed into HAGBs (equiaxed grains) [37]. From $\mathrm{MSR}_{1}$ to $\mathrm{MSR}_{3}$, the increase of $\{101\}$ oriented grains indicates that dynamic recovery (recrystallization) was gradually weakened (Figure 4(c1-c3)). The higher the deformation temperature is, the higher the activity of dislocations and (sub)grain boundaries will be, and it is easier for their migration and merging. Moreover, $\mathrm{MSR}_{1}\left(300{ }^{\circ} \mathrm{C}, 20 \%+400{ }^{\circ} \mathrm{C}, 60 \%\right)$ mainly deformed at high temperature compared with $\mathrm{MSR}_{3}\left(300{ }^{\circ} \mathrm{C}, 60 \%+400{ }^{\circ} \mathrm{C}, 20 \%\right.$ ) leading to more severe dynamic recovery, and more obvious grain refinement.

Figure 5 shows the XRD spectrum and precipitation statistics of $7055 \mathrm{Al}$ alloy treated by different processes. It can be seen that the second phase particles after pre-deformation are mainly $\mathrm{MgZn}_{2}$, which is consistent with the SAED in Figure 3(b1) and EDS results in Figure 3(b3) (Figure 5a). After different pre-deformations at $300{ }^{\circ} \mathrm{C}$, the intensity of $\mathrm{MgZn}$, peak remained almost the same, which reflects the similar precipitate content (i.e., area fraction) [38]. This is consistent with the statistical trend in Figure 5d. Figure 5b shows the XRD spectrum of $7055 \mathrm{Al}$ alloy after SIA. As the intermediate annealing temperature $\left(430^{\circ} \mathrm{C}\right)$ is close to the solution temperature $\left(475^{\circ} \mathrm{C}\right)$, compared with the peak of pre-deformation (Figure 5a), the diffraction peak intensity of SIA is weakened, indicating that precipitates were re-dissolved during SIA. However, the annealing time is short (5 min), so the 
redissolution maybe insufficient. Moreover, the intensity of $\mathrm{MgZn}_{2}$ diffraction peaks in Figure $5 \mathrm{~b}$ decrease with the increased pre-deformation $(20 \rightarrow 60 \%)$ in the SIA stage, which may be related to the increased defects accelerating precipitate re-dissolution. Furthermore, from the XRD spectrum of the finally rolled alloy (Figure $5 \mathrm{c}$ ), with the reduced final rolling deformation (from $\mathrm{MSR}_{1}$ to $\mathrm{MSR}_{3}$ $60 \rightarrow 20 \%$ ), the intensity of $\mathrm{MgZn}_{2}$ peak gradually decreases, indicating the decreased $\mathrm{MgZn}_{2}$ content. Similarly, this is consistent with the statistical trend in Figure $5 \mathrm{~d}$. Low pre-deformation temperature and weak dynamic recovery can lead to more introduction of defects, and accelerate the redissolution of precipitates, so the content of $\mathrm{MgZn}_{2}$ decreases with the decreased final rolling deformation.
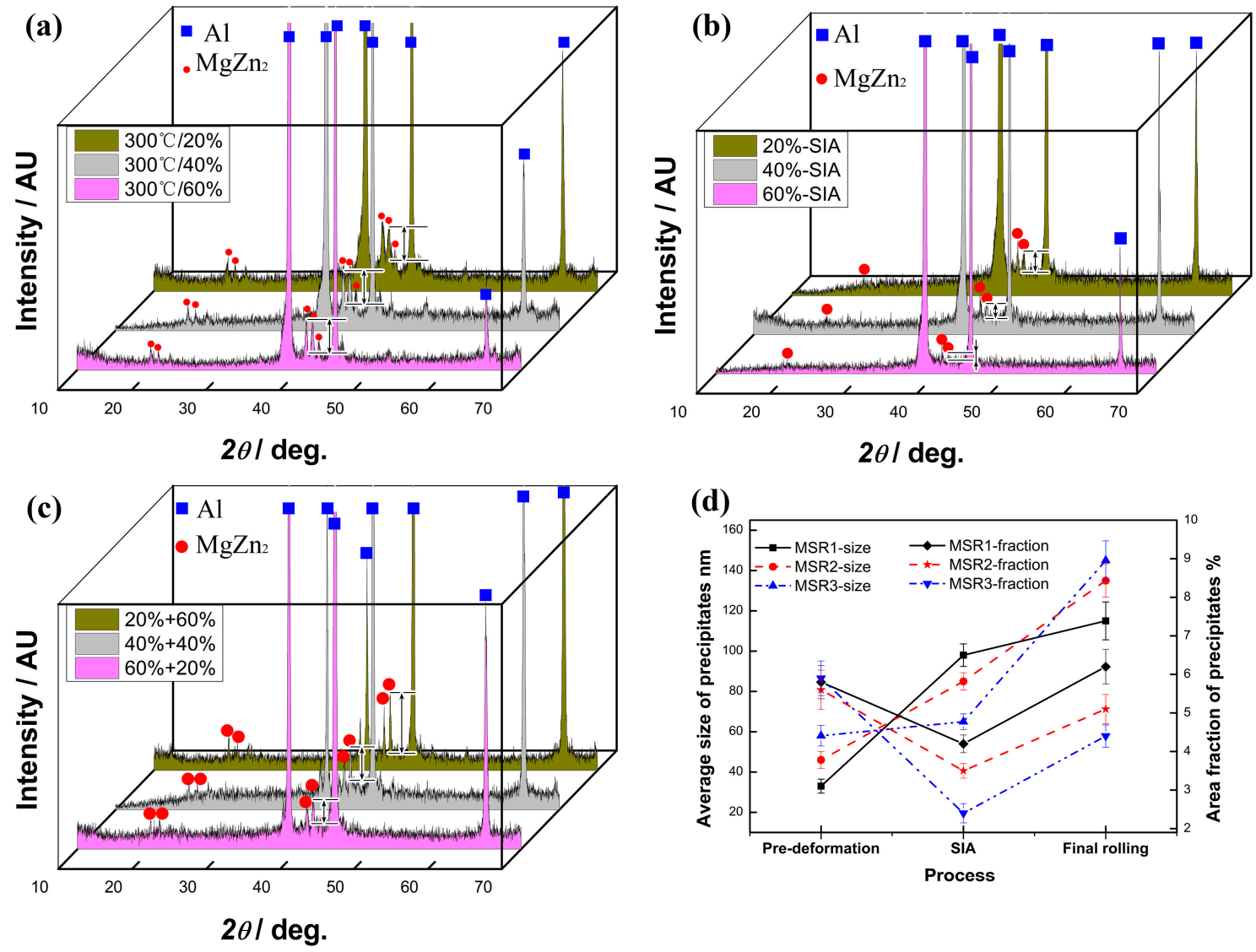

Figure 5. XRD patterns of alloys: (a) after pre-deformation, (b) after SIA, and (c) after the final hot rolling; (d) statistics of average size and area fraction of precipitates.

\subsection{Analysis of Grain Refinement}

To sum up, grain refinement is mainly achieved by dislocation cancellation and rearrangement, which transforms LAGBs into HAGBs. Precipitates play an important role during the whole process. Many models have been used to describe the effects of particles/precipitates and substructures on grain refinement [39,40]. According to these models and the analysis results in Section 3.2, the specific process of grain refinement in MSR can be summarized as follows: (1) Plenty of spherical precipitates wrapped by dislocations were produced during pre-deformation at $300^{\circ} \mathrm{C}$. After further recovery, dislocation cells were formed, seen in Figure 4(a1-a3) and Figure 6b; (2) During SIA treatment, the activity of dislocations increased, while precipitates partially dissolved, resulting in weakening of the pinning effect. Dislocations become ordered and rearranged to form subgrains, as shown in Figure 4(b1-b3) and Figure 6c; (3) In the high temperature final rolling stage, the accumulated strain increased, and the grains further elongated (Figure $4(\mathrm{c} 1-\mathrm{c} 3)$ ). Due to the pinning of precipitates and the accumulation of strain (absorption of defects such as dislocations), sub-grain boundaries gradually stabilized, and LAGBs transformed into HAGBs, with a reduced proportion of LAGBs (Figure 6e,f). Fine equiaxed 
grains appeared near original grain boundaries, so as to realize grain refinement (Figure 4(c1-c3) and Figure 6e,f).

(a)

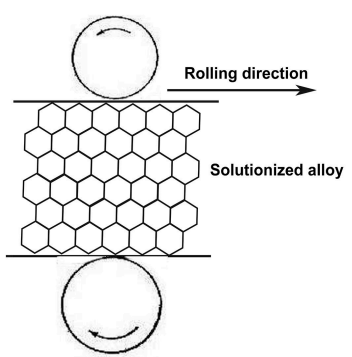

(f)

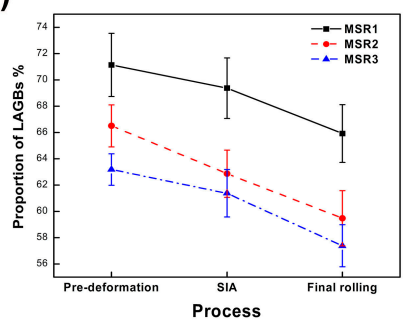

(b)

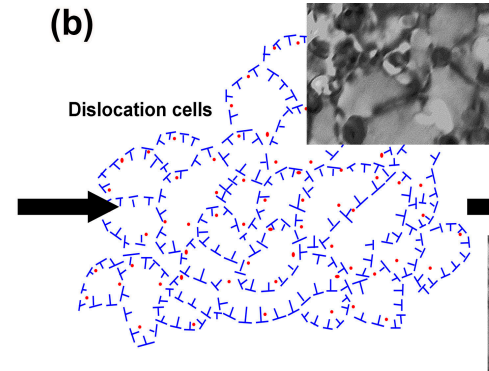

(e)
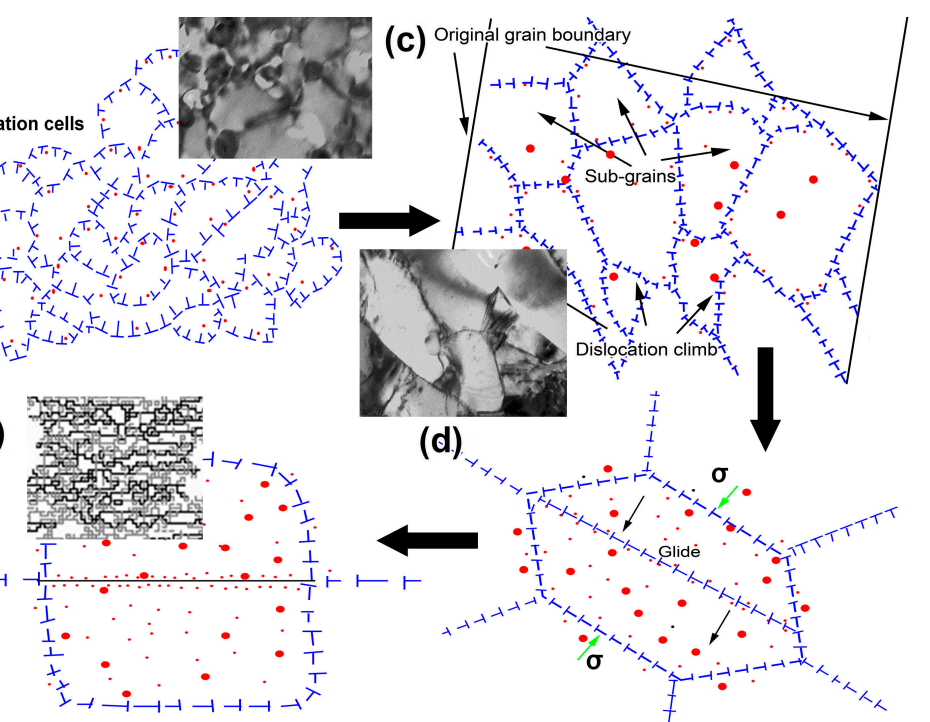

(d)

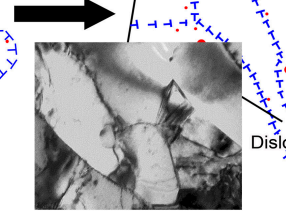

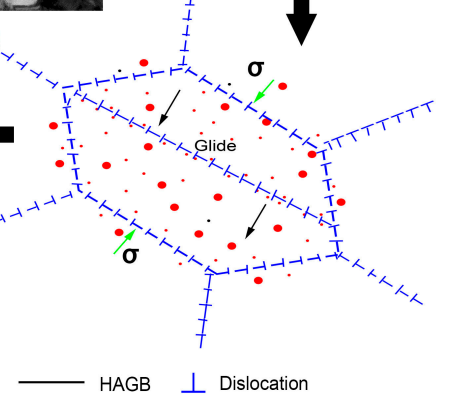

- Fine dispersed Al3Zr or MgZn2 - coarsened MgZn2 — HAGB $\perp$ Dislocation

Figure 6. Schematic diagram of grain refinement: (a) deformation induced by rolling; (b) after pre-deformation; (c) after SIA; (d) with further hot deformation; (e) after final hot rolling; (f) statistical diagram of LAGBs.

\subsection{Microstructure and Mechanical Properties of the Rolled Sheets after Solution and Aging Treatment}

Figure 7 shows OM and EBSD maps of $7055 \mathrm{Al}$ alloy (processed by CHR and MSR) after solution treatment at $475{ }^{\circ} \mathrm{C}$ for $0.5 \mathrm{~h}$. Typical recrystallization structures were formed by both processes, but the former (CHR) was extremely uneven (Figure $7(\mathrm{~d} 1, \mathrm{~d} 2)$ ), with more elongated banded structures and less equiaxed grains (diameter about $35 \mu \mathrm{m}$ ). However, MSR plates show different degrees of grain refinement, the specific grain size is shown in Figure 8c. Grain refinement of $\mathrm{MSR}_{1}$ was the most obvious with plenty of fine equiaxed grains and uniform grain size. Less strip structures with more equiaxed grains appeared in MSR ${ }_{1}$. Some LAGBs appear in the grain interior. From $\mathrm{MSR}_{1}$ to $\mathrm{MSR}_{3}$, the length of the recrystallized grains increased, while the width decreased with the decreased final rolled deformation $(80 \rightarrow 20 \%)$, while the quantity of fine equiaxed grains decreased (Figure 7(a1-c1) and Figure 8c), which means the effect of grain refinement was weakened.

Room temperature tensile engineering stress-strain curves, and the ultimate tensile strength (UTS), yield strength (YS), and elongation ( $\delta$ ), of all rolled plates after solution and T6 aging are shown in Figure $8 \mathrm{a}, \mathrm{b}$. The tensile strength and elongation of CHR alloy are $605 \mathrm{MPa}$ and $14 \%$, respectively, while that of $\mathrm{MSR}_{1}$ alloy are $604 \mathrm{MPa}$ and $18.2 \%$ (specimens break after a certain necking stage). Due to the same solution aging process, the difference of mechanical properties is mainly related to the difference of microstructure caused by TMPs. It has been proved that grain refinement plays a limited role in improving strength of precipitation strengthening alloys, like 7xxx series $\mathrm{Al}$ alloy [17,22,29]. In another way, grain refinement can increase the quantity of grains per unit volume, reduce the nucleation of crack, and increase the resistance to crack propagation [25]. The coordination between grains during plastic deformation in equiaxed fine-grained samples is better than that in coarse-grained samples, leading to more uniform deformation, so as to increase the resistance of crack initiation, improve the dislocation storage capacity and elongation of the alloy. Therefore, the plasticity of fine-grained alloy is much higher than that of coarse-grained alloy. 

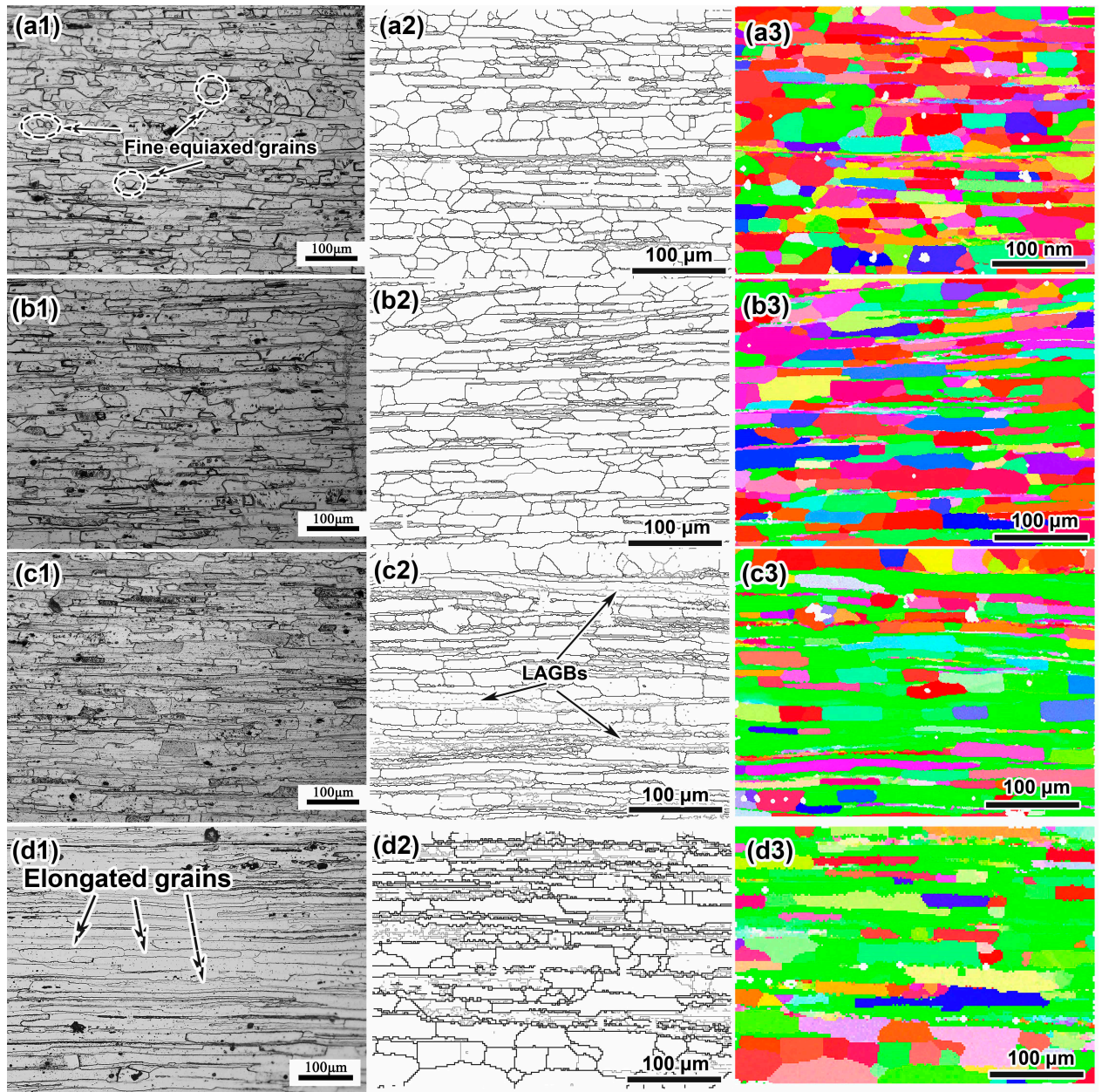

Figure 7. OM (a1-d1) and EBSD maps (a2-d2 for grain boundaries, a3-d3 for grain orientations) of alloys after recrystallization: (a) $\mathrm{MSR}_{1} ;$ (b) $\mathrm{MSR}_{2} ;$ (c) $\mathrm{MSR}_{3} ;$ (d) $\mathrm{CHR}$.
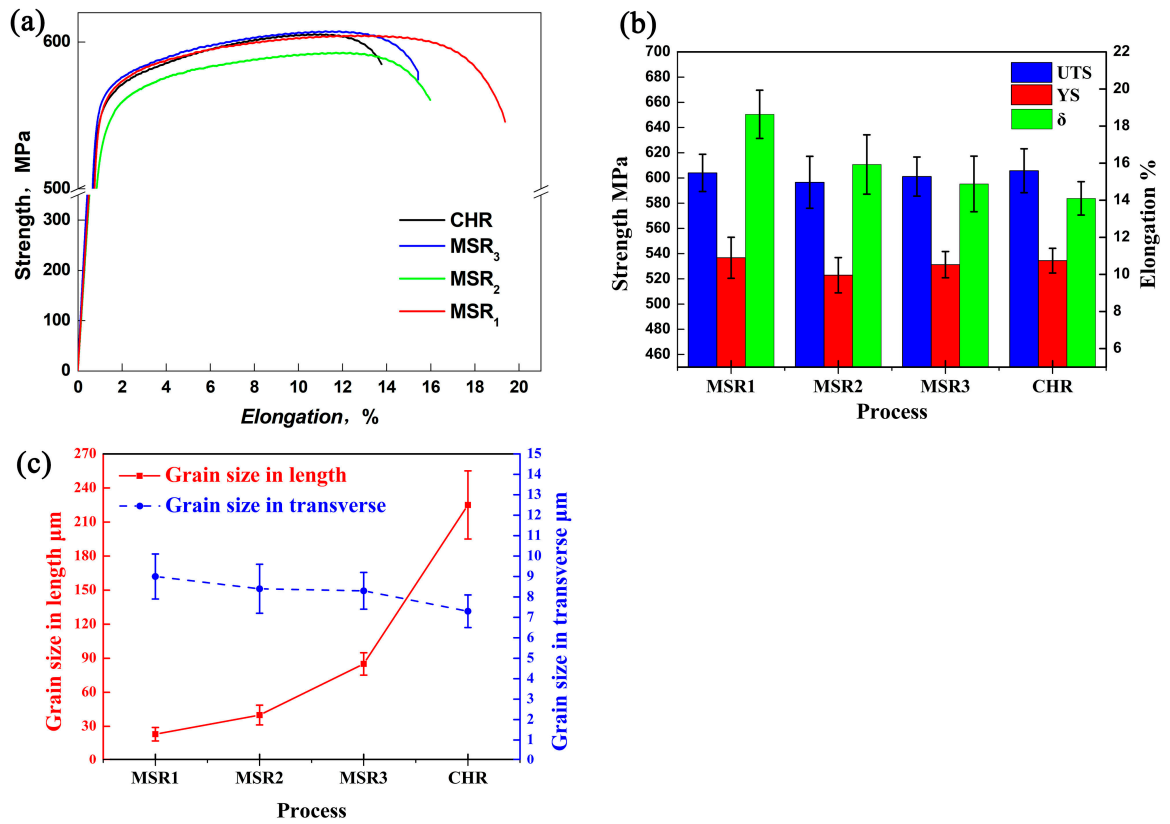

Figure 8. (a) Engineering stress-strain curves; (b) the UTS (Ultimate tensile strength), YS (yield strength) and $\delta$ (elongation) of all processed alloys after T6 aging; (c) the average grain size after recrystallization. 
Figure 9 shows the fracture surface of the MSR 1 sample (with the highest elongation) and CHR sample (with the lowest elongation), respectively. The fracture morphology is closely related to the fracture mode and plasticity. As shown in Figure $9(\mathrm{~b} 1, \mathrm{~b} 2)$, the fracture surface of the CHR sample is relatively smooth with an obvious "fluvial step" structure. A small amount of coarse dimples also appear on the CHR fracture surface, with crushed coarse particles inside them, which indicates that CHR alloy is mainly brittle transgranular fracture mode. However, in the MSR $_{1}$ alloy (Figure 9(a1,a2)), a large quantity of fine dimples and tearing edges can be seen, with a quite uneven fracture surface. This means the crack propagation direction changes many times during the tensile fracture process. The fracture mode of $\mathrm{MSR}_{1}$ is a mixture of transgranular fracture (a great deal of fine deep dimples) and intergranular fracture (plenty of tearing edges). Between them, transgranular fracture is dominant, which indicates that $\mathrm{MSR}_{1}$ alloy is ductile fracture. Therefore, the plasticity (elongation) of $\mathrm{MSR}_{1}$ alloy is much higher than that of $\mathrm{CHR}$.
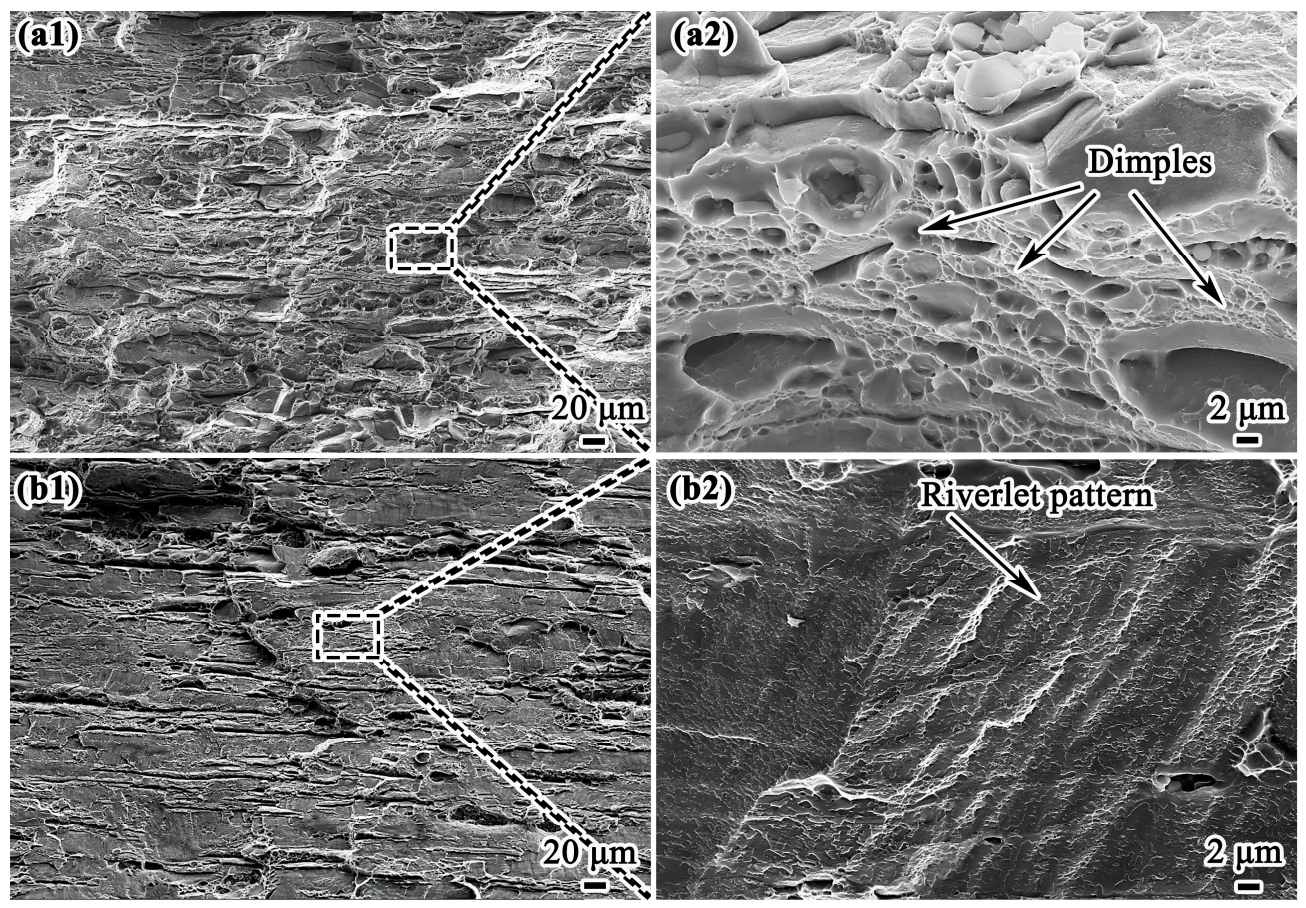

Figure 9. Fracture surfaces of the failed T6 specimens: $(\mathbf{a} 1, \mathbf{a} 2) \mathrm{MSR}_{1} ;(\mathbf{b 1}, \mathbf{b} 2) \mathrm{CHR}$.

\section{Conclusions}

In this paper, a new thermomechanical process (pre-deformation + short period intermediate annealing + final hot rolling) based on deformation induced precipitates was investigated, as well as the effect of parameters on precipitates. The main conclusions can be summarized as follows:

(1) With increased pre-deformation, precipitates were spheroidized gradually with increased size and decreased density, but the area fraction remained almost the same. However, further increased pre-deformation $(60 \rightarrow 80 \%)$ will increase the size of precipitates and weaken the pinning effect on dislocations, which is not conducive to grain refinement in subsequent processes.

(2) Dislocations induced by pre-deformation were entangled and recovered to form dislocation cells. The spheroidized $\mathrm{MgZn}_{2}$ particles pinned dislocations and boundaries, which led to the formation of numerous subgrains during the short period intermediate annealing. The transformation of low angle grain boundaries into high angle grain boundaries could have been accelerated by the pinning effect of precipitates and accumulated deformation during further hot rolling. The optimum TMP for grain refinement was obtained: solid solution + pre-deformation $\left(300{ }^{\circ} \mathrm{C} / 20 \%\right)+$ intermediate annealing $\left(430^{\circ} \mathrm{C} / 5 \mathrm{~min}\right)+$ hot deformation $\left(400{ }^{\circ} \mathrm{C} / 60 \%\right)$. 
(3) The plasticity of alloys can be obviously improved by grain refinement. In particular, the elongation of the $\mathrm{MSR}_{1}$ samples in $\mathrm{T} 6$ state could be increased by $25 \%$ compared with those of the CHR sample. Grain refinement plays a key role.

Author Contributions: Conceptualization, J.Z. (Jinrong Zuo), L.H. and J.Z. (Jishan Zhang); methodology, J.Z. (Jinrong Zuo) and W.P.; formal analysis, J.Z. (Jinrong Zuo); investigation, J.Z. (Jinrong Zuo), X.S. and A.Y.; writing - original draft preparation, J.Z. (Jinrong Zuo); writing-review and editing, L.H., X.S., W.P., A.Y. and J.Z. (Jishan Zhang); visualization, J.Z. (Jinrong Zuo), X.S., W.P. and A.Y.; supervision, X.S. and J.Z. (Jishan Zhang); project administration, X.S. and J.Z. (Jishan Zhang). All authors have read and agreed to the published version of the manuscript.

Funding: This research is supported by the Natural Science Foundation of Zhejiang (No. LQ19E010003), the Major State Research and Development Program of China (No. 2016YFB0300801), the State Key Laboratory for Advanced Metals and Materials of China (No. 2019-Z16), and Sponsored by the K.C. Wong Magna Fund in Ningbo University.

Conflicts of Interest: The authors declare no conflict of interest.

\section{References}

1. Vincze, G.; Simões, F.J.; Butuc, M.C. Asymmetrical rolling of aluminum alloys and steels: A review. Metals 2020, 10, 1126. [CrossRef]

2. Rambabu, P.; Prasad, N.E.; Kutumbarao, V.V.; Wanhill, R.J.H. Aluminium Alloys for Aerospace Applications; Springer: Singapore, 2017.

3. Ghosh, A.; Ghosh, M.; Gudimetla, K.; Kalsar, R.; Kestens, L.A.I.; Kondaveeti, C.S.; Ravisankar, B. Development of ultrafine grained $\mathrm{Al}-\mathrm{Zn}-\mathrm{Mg}-\mathrm{Cu}$ alloy by equal channel angular pressing: Microstructure, texture and mechanical properties. Arch. Civ. Mech. Eng. 2020, 20,1-17. [CrossRef]

4. Shafei, M.A.; Hosseinipour, S.J.; Rajabi, M. Microstructural characterization of nanostructured Al-Zn-Mg-Cu alloy during mechanical alloying and subsequent annealing. Adv. Mat. Res. 2013, 829, 57-61. [CrossRef]

5. Li, H.; Cao, F.; Guo, S.; Jia, Y.; Zhang, D.; Liu, Z. Effects of Mg and Cu on microstructures and properties of spray-deposited Al-Zn-Mg-Cu alloys. J. Alloy. Compd. 2017, 719, 89-96. [CrossRef]

6. Zhang, H.; Li, L.; Yuan, D.; Peng, D. Hot deformation behavior of the new Al-Mg-Si-Cu aluminum alloy during compression at elevated temperatures. Mater. Charact. 2007, 58, 168. [CrossRef]

7. Tang, J.; Zhang, H.; Teng, J.; Fu, D.; Jiang, F. Effect of Zn content on the static softening behavior and kinetics of Al-Zn-Mg-Cu alloys during double-stage hot deformation. J. Alloy. Compd. 2019, 806, 1081-1096. [CrossRef]

8. Yu, H.; Xin, Y.; Wang, M.; Liu, Q. Hall-Petch relationship in Mg alloys: A review. J. Mater. Sci. Technol. 2017, 34, 248-256. [CrossRef]

9. Huang, T.; Shuai, L.; Wakeel, A.; Wu, G.; Hansen, N.; Huang, X. Strengthening mechanisms and hall-Petch stress of ultrafine grained Al-0.3\%Cu. Acta Mater. 2018, 156, 369-378. [CrossRef]

10. Lotkov, A.; Baturin, A.; Kopylov, V.; Grishkov, V.; Laptev, R. Structural defects in TiNi-based alloys after warm ECAP. Metals 2020, 10, 1154. [CrossRef]

11. Xing, J.; Soda, H.; Yang, X.; Miura, H.; Sakai, T. Ultra-fine grain development in an AZ31 magnesium alloy during multi-directional forging under decreasing temperature conditions. Mater. Trans. 2005, 46, 1646-1650. [CrossRef]

12. Shi, J.T.; Hou, L.G.; Zuo, J.R.; Zhuang, L.Z.; Zhang, J.S. Cryogenic rolling-enhanced mechanical properties and microstructural evolution of 5052 Al-Mg alloy. Mat. Sci. Eng. A 2017, 701, 274-284. [CrossRef]

13. Wang, X.F.; Guo, M.X.; Chen, Y.; Zhu, J.; Zhang, J.S.; Zhuang, L.Z. Effect of thermomechanical processing on microstructure, texture evolution, and mechanical properties of Al-Mg-Si-Cu alloys with different zn contents. Metall. Mater. Trans. A 2017, 48, 3540-3558. [CrossRef]

14. Yi, S.; Victoria-Hernandez, J.; Kim, Y.M.; Letzig, D.; You, B.S. Microstructure and property relationship controllable by thermomechanical processing of Mg-Al-Zn-Y-Ca alloy sheets. Acta Phys. Pol. A 2018, 134, 838-841. [CrossRef]

15. Yan, L.M.; Shen, J.; Li, Z.B.; Li, J.P. Effect of deformation temperature on microstructure and mechanical properties of 7055 aluminum alloy after heat treatment. Trans. Nonferrous Met. Soc. China 2013, 23, 625-630. [CrossRef] 
16. Russo, E.D.; Conserva, M.; Buratti, M.; Gatto, F. A new thermo-mechanical procedure for improving the ductility and toughness of AlZnMgCu alloys in the transverse directions. Mat. Sci. Eng. 1974, 14, 23-36. [CrossRef]

17. Waldman, J.; Sulinski, H.; Markus, H. The effect of ingot processing treatments on the grain size and properties of Al alloy 7075. Metall. Mater. Trans. B 1974, 5, 573. [CrossRef]

18. Wert, J.A.; Paton, N.E.; Hamilton, C.H.; Mahoney, M.W. Grain refinement in 7075 aluminum by thermomechanical processing. Metall. Mater. Trans. A 1981, 12, 1267. [CrossRef]

19. Esmaeili, S.; Lloyd, D.J.; Jin, H. A thermomechanical process for grain refinement in precipitation hardening AA6xxx aluminum alloys. Mater. Lett. 2011, 65, 1028-1030. [CrossRef]

20. Robson, J.D. Microstructural evolution in aluminium alloy 7050 during processing. Mat. Sci. Eng. A 2004, 382, 112-121. [CrossRef]

21. Li, X.M.; Starink, M.J. Effect of compositional variations on characteristics of coarse intermetallic particles in overaged 7000 series aluminium alloy. Mater. Sci. Technol. 2001, 17, 1324-1328.

22. Knipling, K.E.; Dunand, D.C.; Seidman, D.N. Criteria for developing castable, creep-resistant aluminum-based alloys-A review. Z. Met. 2006, 97, 246-265. [CrossRef]

23. Zuo, J.R.; Hou, L.G.; Shu, X.D.; Peng, W.F.; Yin, A.M.; Zhang, J.S. Grain refinement assisted by deformation enhanced precipitates through thermomechanical treatment of AA7055 al alloy. Metals 2020, 10, 594. [CrossRef]

24. Zuo, J.R.; Hou, L.G.; Shi, J.T.; Cui, H.; Zhuang, L.Z.; Zhang, J.S. Effect of deformation induced precipitation on grain refinement and improvement of mechanical properties AA 7055 aluminum alloy. Mater. Charct. 2017, 130, 123-134. [CrossRef]

25. Yu, D. Effect of interstage homogenizing treatment on homogenization degree and overburnt temperature of 7AO4 alloy. Alum. Fabr. 2003, 3, 23-26.

26. Freiberg, D.; Zhu, W.; Park, J.S.; Almer, J.D.; Sanders, P. Precipitate characterization in model Al-Zn-Mg-(Cu) alloys using small-angle X-ray scattering. Metals 2020, 10, 959. [CrossRef]

27. Zuo, J.R.; Hou, L.G.; Shi, J.T.; Cui, H.; Zhuang, L.Z.; Zhang, J.S. Effect of deformation induced precipitation on dynamic aging process and improvement of mechanical/corrosion properties AA7055 aluminum alloy. J. Alloy. Compd. 2017, 708, 1131-1140. [CrossRef]

28. Zuo, J.R.; Hou, L.G.; Shi, J.T.; Cui, H.; Zhuang, L.Z.; Zhang, J.S. Enhanced plasticity and corrosion resistance of high strength Al-Zn-Mg-Cu alloy processed by an improved thermomechanical processing. J. Alloy. Compd. 2017, 716, 220-230. [CrossRef]

29. Zuo, J.R.; Hou, L.G.; Shi, J.T.; Cui, H.; Zhuang, L.Z.; Zhang, J.S. The mechanism of grain refinement and plasticity enhancement by an improved thermomechanical treatment of $7055 \mathrm{Al}$ alloy. Mat. Sci. Eng. A 2017, 702, 42-52. [CrossRef]

30. Liddicoat, P.V.; Liao, X.-Z.; Zhao, Y.; Zhu, Y.; Murashkin, M.Y.; Lavernia, E.J. Nanostructural hierarchy increases the strength of aluminium alloys. Nat. Commun. 2010, 1, 63. [CrossRef]

31. Doherty, R.D. Physical metallurgy. In Physical Metallurgy; Cahn, R.W., Haasen, P., Eds.; North-Holland: Oxford, UK, 1996; pp. 1363-1505.

32. Yu, Y.N. Principles of Metallurgy; Metallurgical Industry Press: Beijing, China, 2000; pp. 481-490.

33. Yujing, L. Grain Refinement of 7050 Aluminum Alloy and Its Mechanical Behavior by Hot Deformation Based on Strain-Induced Precipitation. Ph.D. Thesis, University of Science and Technology, Beijing, China, 2012.

34. Zener, C. Theory of growth of spherical precipitates from solid solution. Appl. Phys. Lett. 1949, $20,950$. [CrossRef]

35. Chalendar, J.A.; de Garing, C.; Benson, S.M. Pore-scale modelling of Ostwald ripening. J. Fluid. Mech. 2018, 835, 363-392. [CrossRef]

36. Hurley, P.J.; Humphreys, F.J. The application of EBSD to the study of substructural development in a cold rolled single-phase aluminium alloy. Acta Mater. 2003, 51, 1087. [CrossRef]

37. Sakai, T.; Miura, H.; Goloborodko, A.; Sitdikov, O. Ultrafine grain formation in ferritic stainless steel during severe plastic deformation. Acta Mater. 2009, 57, 153. [CrossRef]

38. Lang, Y.J.; Cui, H.; Cai, Y.H.; Zhang, J.S. Effect of strain-modified particles on the formation of fined grains and the properties of AA7050 alloy. Mater. Design 2012, 39, 220. [CrossRef] 
39. Lang, Y.J.; Zhou, G.; Hou, L.G.; Zhang, J.S.; Zhuang, L.Z. Significantly enhanced the ductility of the fine-grained Al-Zn-Mg-Cu alloy by strain-induced precipitation. Mater. Des. 2015, 88, 625-631. [CrossRef]

40. Huo, W.T.; Hou, L.G.; Zhang, Y.; Zhang, J.S. Warm formability and post-forming microstructure/property of high-strength AA 7075-T6 Al alloy. Mat. Sci. Eng. A 2016, 675, 44-54. [CrossRef]

Publisher's Note: MDPI stays neutral with regard to jurisdictional claims in published maps and institutional affiliations.

(C) 2020 by the authors. Licensee MDPI, Basel, Switzerland. This article is an open access article distributed under the terms and conditions of the Creative Commons Attribution (CC BY) license (http://creativecommons.org/licenses/by/4.0/). 